This article was downloaded by: [KU Leuven University Library]

On: 08 October 2013, At: 01:45

Publisher: Routledge

Informa Ltd Registered in England and Wales Registered Number: 1072954 Registered office: Mortimer House, 37-41 Mortimer Street, London W1T 3J H, UK

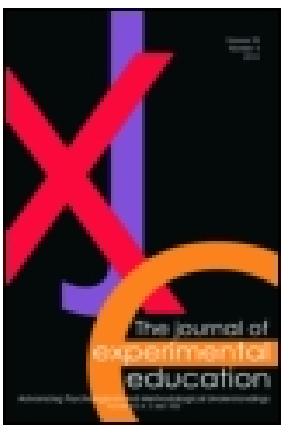

The J ournal of Experimental Education

Publication details, including instructions for authors and subscription information:

http:// www. tandfonline.com/loi/ vjxe20

\title{
The Impact of Illustrations and Warnings on Solving Mathematical Word Problems Realistically
}

\author{
Tinne Dewolf $^{a}$, Wim Van Dooren ${ }^{a}$, Emre Ev Cimen ${ }^{\mathrm{a}}{ }^{\mathrm{b}}$ \& Lieven \\ Verschaffel $^{a}$ \\ ${ }^{a}$ Katholieke Universiteit (KU) Leuven, Belgium \\ ${ }^{\mathrm{b}}$ Eskişir Osmangazi University, Turkey \\ Published online: $17 \mathrm{~J}$ ul 2013.
}

To cite this article: Tinne Dewolf , Wim Van Dooren, Emre Ev Cimen \& Lieven Verschaffel , The J ournal of Experimental Education (2013): The Impact of Illustrations and Warnings on Solving Mathematical Word Problems Realistically, The J ournal of Experimental Education, DOI: 10. 1080/ 00220973. 2012.745468

To link to this article: http:// dx.doi.org/ 10.1080/00220973.2012.745468

\section{PLEASE SCROLL DOWN FOR ARTICLE}

Taylor \& Francis makes every effort to ensure the accuracy of all the information (the "Content") contained in the publications on our platform. However, Taylor \& Francis, our agents, and our licensors make no representations or warranties whatsoever as to the accuracy, completeness, or suitability for any purpose of the Content. Any opinions and views expressed in this publication are the opinions and views of the authors, and are not the views of or endorsed by Taylor \& Francis. The accuracy of the Content should not be relied upon and should be independently verified with primary sources of information. Taylor and Francis shall not be liable for any losses, actions, claims, proceedings, demands, costs, expenses, damages, and other liabilities whatsoever or howsoever caused arising directly or indirectly in connection with, in relation to or arising out of the use of the Content.

This article may be used for research, teaching, and private study purposes. Any substantial or systematic reproduction, redistribution, reselling, loan, sub-licensing, systematic supply, or distribution in any form to anyone is expressly forbidden. Terms \& Conditions of access and use can be found at http://www.tandfonline.com/page/termsand-conditions 


\title{
LEARNING, INSTRUCTION, AND COGNITION
}

\section{The Impact of Illustrations and Warnings on Solving Mathematical Word Problems Realistically}

\author{
Tinne Dewolf, Wim Van Dooren, Emre Ev Cimen, and Lieven Verschaffel \\ Katholieke Universiteit (KU) Leuven, Belgium
}

\begin{abstract}
The present research investigated whether an illustration and/or a warning could help students to (a) build a situational model of the problem situation and (b) solve problematic word problems $(P$-items) that require realistic thinking more realistically. In 2 similar studies conducted in Turkey and Belgium, the authors presented 10- to 11-year-old children with several $P$-items. These problems were accompanied with an illustration that depicted the problem situation and/or a warning that alerted that some items may be nonstandard. Contrary to the authors' expectation, findings from both studies showed that neither the illustration nor the warning, or even the combination of both manipulations, had a positive impact on the number of realistic reactions.
\end{abstract}

Keywords mathematics education, problem solving, elementary school, reasoning, critical thinking

MATHEMATICS PROVIDES A SET OF TOOLS for describing, analyzing, and predicting the behavior of systems in different domains of the real world (Burkhardt, 1994). It helps people to understand the world around them, to cope with everyday problems, and to prepare for future professions. This practical usefulness of mathematics provides a major justification for the important role of mathematics in the (elementary) school curriculum (Blum \& Niss, 1991). In particular, the inclusion of application problems - problems in which "the situation and the questions defining it belong to some segment of the real world and allow some mathematical concepts, methods and results to become involved" (Blum \& Niss, 1991, p. 37)—was and still is

Emre Ev Cimen is now affiliated with Eskişir Osmangazi University in Turkey.

The authors thank Tugce Tosun for the illustrations that were used in this research. They also thank Kamil Beki, Yaşar Şişman, Hüsamettin Oztütüncü, Annemie Van Der Smissen, and Liesbeth Velghe for their help in the collection and analysis of the data.

This study was funded by the GOA grant 2012/010 "Number sense: Analysis and improvement" from the Research Fund KU Leuven, Belgium.

Address correspondence to Tinne Dewolf, Centre for Instructional Psychology and Technology, KU Leuven, Dekenstraat 2, Box 3773, 3000 Leuven, Belgium. E-mail: tinne.dewolf@ppw.kuleuven.be 
mainly intended to learn how to apply one's mathematical skills effectively in different (problem) situations encountered in daily life. This way, students can practice situations of everyday life in which they need their mathematical knowledge, without the trouble of direct contact with the real world (Verschaffel, Greer, \& De Corte, 2000).

In the past, one major way to bring the real world into the mathematics classroom and to teach mathematical modeling and applied problem solving was through word problems. Word problems are "verbal descriptions of problem situations, typically presented in a school context, wherein a question is raised the answer to which can be found by performing mathematical operation(s) with the numbers in the problem" (Verschaffel et al., 2000, p. ix). It was assumed that word problems, as particular kind of application problems, would foster a realistic approach toward mathematical modeling and applied problem solving. However, during the past two decades, many authors have argued that because of several years of schooling, students approach word problems in an unrealistic and artificial way, and they execute arithmetic operations with the numbers given in the problem without making any serious realistic considerations (Lave, 1992; Nesher, 1980; Reusser \& Stebler, 1997a; Schoenfeld, 1991; Verschaffel et al., 2000; Verschaffel, Greer, Van Dooren, \& Mukhopadhyay, 2009).

To support this claim, Greer (1993) and Verschaffel, De Corte, and Lasure (1994) confronted in two related studies upper-primary and lower-secondary school students, in the context of a typical mathematics lesson or test, with two kinds of word problems: standard problems ( $S$-items) and problematic problems ( $P$-items). $S$-items are problems that can be properly modeled and solved by the routine application of one or more simple arithmetical operations with the numbers given in the problem. For example, "A man cuts his clothesline of $12 \mathrm{~m}$ into pieces of $1.5 \mathrm{~m}$ each. How many pieces does he get?" The correct solution is 12 because $1.5 \mathrm{~m}=8$ pieces. $P$-items are problems that cannot be solved by means of a straightforward application. These problems call for the application of judgments on the basis of real-world knowledge and assumptions, at least if one takes these real-world aspects seriously. For example, "Steve has bought 4 planks that are each $2.5 \mathrm{~m}$ long. How many planks of $1 \mathrm{~m}$ can he get out of these planks?" In this $P$-item, it has to be taken into account that there will be four pieces of $0.5 \mathrm{~m}$ left, which leads to the following answer: $4 \times 2=8$ pieces (instead of $4 \times 2.5=10$ pieces). Although this $P$-item allows for a precise realistically appropriate numerical answer, for other $P$-items, it is difficult or even impossible to give such a precise numerical answer. Instead, they ask for an estimation of the numerical solution or an indication of the solution range. Examples of such $P$-items are "Bruce and Alice go to the same school. Bruce lives at a distance of $17 \mathrm{~km}$ from the school and Alice at $8 \mathrm{~km}$. How far do Bruce and Alice live from each other?" (realistic reaction: You cannot solve this problem because the answer can be either $9 \mathrm{~km}$ or $25 \mathrm{~km}$ or somewhere in between) and "A man wants to have a rope long enough to stretch between two poles $12 \mathrm{~m}$ apart, but he has only pieces of rope $1.5 \mathrm{~m}$ long. How many of these pieces would he need to tie together to stretch between the poles?" (realistic reaction: More than 8 pieces of rope are needed, because of the knots).

In Verschaffel et al.'s (1994) study, for example, upper-primary and low-secondary school students were presented with a paper-and-pencil test consisting of ten pairs of an $S$-item and a parallel $P$-item (as in the aforementioned examples). Students had to answer each item and were invited to comment on the problem and/or on their response. A reaction to a $P$-item was classified as a nonrealistic reaction if the answer was the result of a straightforward, unrealistic execution of the operation, without any comments about the problematic nature of the problem. In contrast, a reaction to 
a $P$-item was classified as a realistic reaction if the answer given indicated that realistic considerations had been taken into account in the solution to the problem, or if the answer was accompanied by a comment indicating that the student was aware that the problem was not straightforward. For example, for the planks $P$-item mentioned earlier, the classification of realistic response is given to a student who gave the realistic answer " 8 " or who responded that it was not possible to answer the problem because of the unclarity about what should or could be done with the remaining pieces of $0.5 \mathrm{~m}$. Also, the straightforward nonrealistic answer " $4 \times 2.5=10$ " followed by the realistic comment "But Steve would have a hard time putting together the remaining pieces of $0.5 \mathrm{~m}$ " is classified as a realistic response. In contrast, a response of " 10 " without any additional comment referring to the realistic constraints of the problem situation is classified as a nonrealistic reaction. For a detailed overview of the scoring rules for all P-items, see Verschaffel et al. (1994).

In both studies (Greer, 1993; Verschaffel et al., 1994), students demonstrated a very strong overall tendency to exclude real-world knowledge and realistic considerations when presented with the problematic items. For example, in Verschaffel et al.'s (1994) study, only $17.0 \%$ of all reactions to the $10 P$-items could be considered as realistic.

The findings of Greer (1993) and Verschaffel et al. (1994) have been replicated in many countries (for an overview, see Verschaffel et al., 2000, 2009). These studies have also been complemented with other investigations in which (groups of) students were questioned in the context of individual or collective debriefs (e.g., Caldwell, 1995; Hidalgo, 1997; Inoue, 2001; Reusser \& Stebler, 1997a). The findings of these latter studies showed that students' lack of sense making when solving arithmetic word problems in a typical school setting is not caused by a strange cognitive deficit. Rather, the cause seems to be students' beliefs about the role of mathematical word problems and how they should be treated and solved in the mathematics class. Students, for example, may believe that all word problems are solvable, that every number is explicitly given in the problem statement, and that every given number is relevant (Caldwell, 1995; Reusser \& Stebler, 1997a; Schoenfeld, 1991; Verschaffel et al., 2000).

On the basis of these findings that students tend to neglect the real world when solving word problems, and that this approach is associated with comprehensible but inappropriate beliefs about word problems and how to solve them, several scholars have tried a number of manipulations of the experimental setting with the goal to break these tactics and beliefs and, consequently, increase the number of realistic reactions (for an overview, see Verschaffel et al., 2000).

A first set of studies investigated the impact of increasing the realism or authenticity of the experimental setting by presenting P-problems as real problems outside of the (typical) mathematics class context. DeFranco and Curcio (1997), for example, presented a division-withremainder problem wherein students were asked to calculate how many buses are needed to take a group of students to a party. The problem was offered in a restrictive scholastic setting, and in a (relatively) real-world setting. In the scholastic setting, almost all students responded incorrectly to the problem, whereas in the real-world setting - wherein students had to make a telephone call to order the buses-almost all students gave a correct, realistic response by correctly interpreting the remainder. Such increased performance outside the context of the mathematics classroom was also observed by Reusser and Stebler (1997b). In their study, students received genuine materials to solve the $P$-items, such as planks, a saw, and measuring tape to solve the planks item. Increased performance was also found by Säljö and Wyndhamn (1993), in which the task of determining how much it would cost to post a letter of a certain weight was given in a mathematics class and a social studies class. 
These three studies showed that by increasing the authenticity of the setting by presenting the problem outside of the mathematics class, students are more likely to perform better on $P$ items. However, in these three studies, the manipulations involved stepping out of the restrictive context of the mathematics class. The question underlying the present study is whether it is possible to increase the number of realistic reactions on $P$-items while staying within the cultural and organizational context of a mathematics class, by complementing the problem text with an illustration that represents the problematic situation of the word problem. To maximize the chance that the addition of an illustration would positively affect students' tendency to respond realistically, we also investigated the effect of including a warning about the nonstandard nature of the problems as a second experimental variable. So, our main hypothesis was that illustrations would positively affect the number of realistic reactions on $P$-items in upper elementary school students, especially when accompanied by a warning.

\section{Previous Research on the Impact of Illustrations}

The role of various kinds of illustrations on students' understanding and solution of classical word problems has been empirically investigated from several different theoretical perspectives. Elia and Philippou (2004), for example, studied the function of pictures in word problem solving. On the basis of the categorization of Carney and Levin (2002), Elia and Philippou (2004) distinguished four functions ${ }^{1}$ : decorative pictures, representational pictures, organizational pictures, and informational pictures. Decorative pictures are pictures that have no relation with the problem and/or its solution; they simply decorate the page. Representational pictures, in contrast, illustrate the problem partly or entirely, for example, by providing a picture that portrays (a relevant part of) the scene that is described in the problem. Organizational pictures are pictures that provide directions that support the identification of (a part of) the solution procedure. Informational pictures, in contrast with the three aforementioned categories, give information that is absolutely essential for the understanding and/or solution of the problem, for example, essential numerical information that is not provided in the problem statement. Elia and Philippou (2004) found that effective problem solving with pictures depends on the function of the picture. Representational, organizational, and informational pictures had a significant effect on problem solving, whereas decorative pictures had no effect. Other studies have also suggested that decorative pictures have no significant role in mathematical problem solving (Agathangelou, Gagatsis, \& Papakosta, 2008; Elia, Gagatsis, \& Demetriou, 2007). The role of representational pictures seems to be ambiguous. There was a positive effect on word problem solving of representational pictures in the study of Elia and Philippou (2004). However, Agathangelou et al. (2008) found that representational pictures did not affect students' performance in mathematical word problem solving.

Besides empirical investigations, researchers have also developed theoretical models about the impact of illustrations. Among the most influential theories or models are Paivio's (1986)

\footnotetext{
${ }^{1}$ Elia and Philippou's (2004) categorization is based on, but somewhat different from, the categorization of Carney and Levin (2002), who distinguished five types of pictures in relation to text processing: decorational, representational, organizational, interpretational, and transformational pictures. Elia and Philippou (2004) adopted the first three categories, linked them to mathematical problem solving, and added the category informational pictures instead of the categories interpretational and transformational pictures in Carney and Levin's (2002) categorization.
} 
dual coding theory, Mayer's (2005) cognitive theory of multimedia learning, and Schnotz and Bannert's (2003) integrated model of text and picture comprehension.

Schnotz and Bannert's (2003) model (see also Schnotz, 2005) was taken as the theoretical framework for the present study (see Figure 1). Their model, which they embedded in a broader framework of human cognition (Schnotz, 2005), was developed in an attempt to predict when and explain why people learn better from words and pictures than from words alone, the so-called multimedia effect (see Mayer, 1997).

When reading a text accompanied by one or more pictures, multiple mental representations are formed in the cognitive system. Information first enters working memory through a sensory register. In the case of reading a text with illustrations, the information goes through the visual channel to the visual working memory. In the visual working memory, verbal information-a perceptual representation of the text-surface structure-is forwarded through the verbal channel to the propositional working memory, where the semantic content of the text is understood. On the basis of this propositional representation, a mental model is constructed. Simultaneously, the pictorial information - a perceptual representation of the illustration-goes through the pictorial

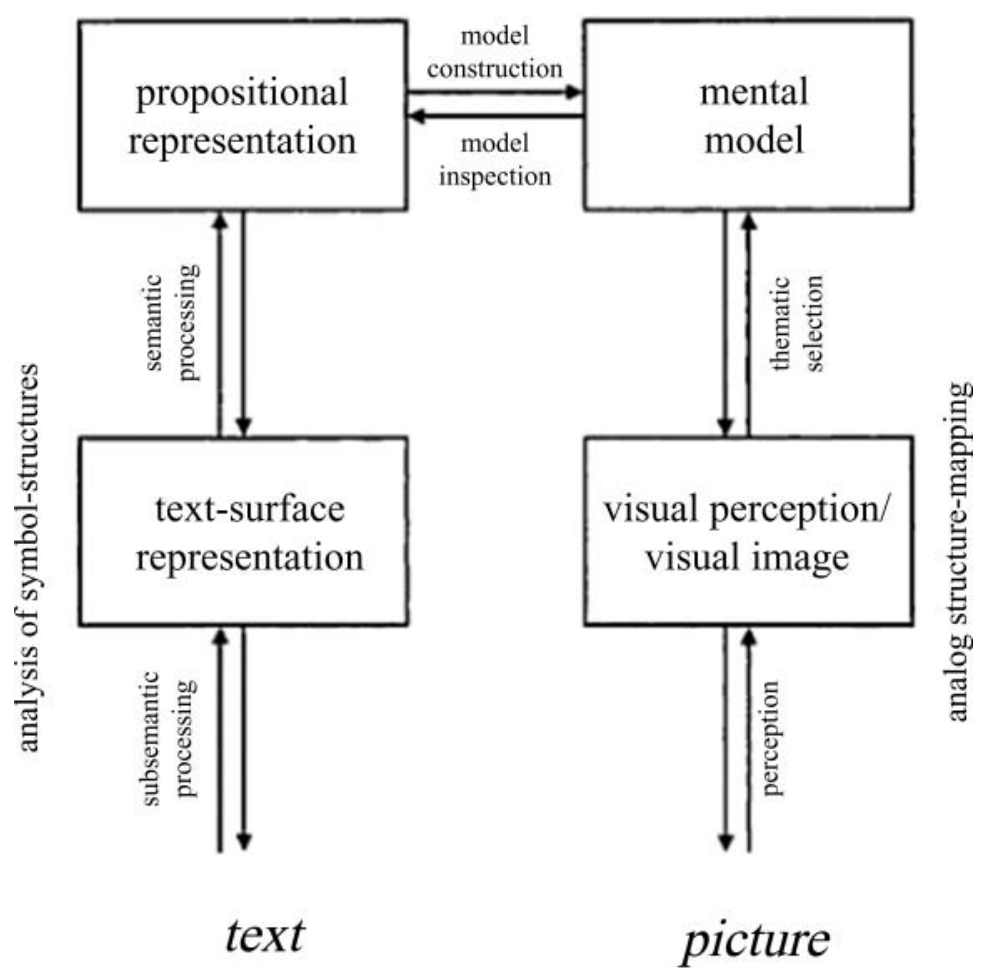

FIGURE 1 Integrated model of text and picture comprehension. Adopted from "An integrated model of text and picture comprehension," by W. Schnotz (2005). In R. E. Mayer (Ed.), The Cambridge handbook of multimedia learning (pp. 49-69). New York, NY: Cambridge University Press. Copyright by Cambridge University Press. Reprinted with permission. 
channel and gets included into the mental model. This mental model can be defined as "a mental representation of a subject matter by an internal structure that is analogous to the subject matter" (Schnotz, 2005, p. 67). It integrates information from both sources, and it interacts continuously with the propositional representations through processes of model inspection and model construction.

This integrated model of text and picture comprehension helps to explain how and why people may learn better from words and pictures than from words alone. It also helps to understand why the positive combined effect of text and pictures is not found under all conditions. The model assumes that the construction of a mental model is facilitated only if (a) text and pictures are semantically related, (b) text and picture information are simultaneously available in working memory, and (c) they are presented close to each other. In one of their experiments, Schnotz and Bannert (2003) provided empirical evidence for the first condition, by showing that taskappropriate graphics support learning whereas task-inappropriate graphics may interfere with the construction of the mental model.

The available empirical and theoretical work on the effect of illustrations in mathematical problem solving has already yielded some interesting findings and insights. It however has not yet explored the impact of representational illustrations on problems with realistic modeling complexities, such as the aforementioned $P$-items. As explained earlier, it is generally claimed that students solve $P$-items nonrealistically because they perceive and approach these problems as artificial puzzle-like tasks bound to the mathematics lesson, that have no direct relationship with the real world (Verschaffel et al., 2000). By providing a rich pictorial description of the problem situation (equivalent to a task-appropriate illustration or a representational illustration, according to the classification of Schnotz and Bannert [2003] and Elia and Philippou [2004], respectively), it is expected that students will construct a richer mental model wherein there is room for context-specific real-world elements and considerations. This mental model is the starting point of the construction of a mathematical model, from which mathematical results and the ultimate answer to the problem are derived. Stated differently, it is expected that the presentation of a representational illustration will prevent students from searching for the standard computation that is hidden in the problem without trying to construct a rich mental model of the situation described in the problem statement.

\section{Previous Research on Effect of Warnings}

As mentioned earlier, we investigated the effect of including a warning about the nonstandard nature of the problems as a second experimental variable. Previous research about this variable has yielded mixed results. Yoshida, Verschaffel, and De Corte (1997) asked a group of Japanese fifth-grade students to solve the problems of Verschaffel et al. (1994). Half of the students received an explicit warning at the top of their test sheet that said that some of the problems in the test were difficult or impossible to solve. The warning also invited students explicitly to write down and explain the unclarities or complexities they encountered. This manipulation only resulted in a small, nonsignificant increase in the number of realistic reactions to the $P$-items in the test. However, a number of other studies have also tested the effectiveness of interventions intended to make students more alert, to sensitize them to the consideration of aspects of reality, or to legitimize alternative forms of answers without fundamentally changing the experimental setting 
(for an overview of these studies, see Chapter 3 of Verschaffel et al., 2000). The overall picture of these investigations suggests that these extra measures may produce, at best, only weak effects. Small but significant effects were especially found when the measure was not restricted to one single general warning at the very beginning of the test, as in the study by Yoshida et al. (1997), but when such a warning attempting "to sow the seeds of doubts about the students' solutions" was repeatedly presented throughout the test or tied to particular problems (Reusser \& Stebler, 1997a; Van Lieshout, Verdwaald, \& Van Herk, 1997; Verschaffel, De Corte, \& Lasure, 1999).

\section{Subject Characteristics}

Some researchers have suggested that students' tendency to ignore plausibly relevant and familiar aspects of reality in answering $P$-items may also be associated with subject characteristics such as age, social class, and gender (Verschaffel, 2002). There is already some empirical evidence in favor of this claim for the two subject features of age and social class (see Verschaffel, 2002). However, the role of gender in students' solutions of $P$-items has, to the best of our knowledge, not yet been investigated. In an empirical study, Boaler (1994) compared girls' and boys' solutions of word problems dealing with topics such as football and fashion. Boaler claimed that girls show greater involvement in the realities of the problem context than boys, especially when they have a lot of experiential knowledge and/or a strong emotional involvement in the problem topic. However, instead of $P$-items, Boaler's (1994) study involved traditional word problems such as the S-items from Verschaffel et al.'s (1994) study. Therefore, we also examined the role of gender in the present study.

\section{The Present Research}

We next report and discuss two closely related studies in which we presented $P$-items together with an illustration and/or a metacognitive warning to investigate whether illustrations would positively affect the number of realistic reactions on $P$-items in upper elementary school students, especially when accompanied by a warning. Both studies involved four conditions in which the $P$-items were presented (a) with an illustration but without a warning $(I+W$ - condition), (b) with only a warning ( $I-W+$ condition), (c) with an illustration and a warning $(I+W+$ condition), and (d) without illustration or warning ( $I-W-$ condition). The studies involved respectively Turkish and Flemish students. The design of the studies, which were done more or less simultaneously, was the same, except for some minor differences caused by practical local constraints (see further).

\section{STUDY 1: A STUDY WITH TURKISH STUDENTS}

\section{Research Question and Hypotheses}

Our main research question was whether upper elementary school students' strong and persistent tendency to react to $P$-items in a nonrealistic way could be overcome by presenting these items in combination with an illustration that pictorially represents the problematic situation (a representational illustration) and/or an alert that warns about the tricky nature of some of the problems. 
So, our first hypothesis stated that more students would solve $P$-items realistically when they are presented with an illustration than without (Hypothesis 1). Relying on Schnotz and Bannert's (2003) integrated model of text and picture comprehension, we expected that the accompanying illustration would help students to create a mental model with a rich and realistic representation of the problem situation and thus lead to a significant increase in the overall number of realistic reactions. Our second hypothesis stated that more students would solve $P$-items realistically when they are presented with a warning than without (Hypothesis 2). On the basis of the available empirical research on the effect of warnings, we expected that a warning would sensitize students to consider different aspects of reality and thus result in more realistic reactions (Reusser \& Stebler, 1997a; Verschaffel et al., 1999). Third, we anticipated that the largest number of realistic reactions would be found in the group receiving $P$-items together with both an illustration and a warning (Hypothesis 3). We expected that when the illustrations are presented together with an alert that warns for the presence of tricky problems that are not as easy as they seem, the illustrations would be more thoroughly processed and therefore the effect would be maximized. Fourth, apart from looking to the overall effect of illustrations and/or a warning, we also looked for differences between boys and girls. Based on Boaler's (1994) study, we expected that girls would react more realistically on the $P$-items than boys (Hypothesis 4). Last, we analyzed whether the presence or absence of illustrations and/or a warning might have a different effect on boys and girls (Hypothesis 5).

\section{Method}

\section{Participants}

Participants were 402 students from 12 fifth-grade classes from three public schools, located in three different regions in Turkey. The age range of the students was between 10 and 11 years. The different classes from each school were randomly assigned to the four experimental conditions; 97 students (48 boys, 49 girls) received the word problems with an illustration but without a warning ( $I+W-$ condition), 108 students (62 boys, 46 girls) without an illustration but with a warning ( $I-W+$ condition), 102 students (59 boys, 43 girls) with an illustration and a warning $(I+W+$ condition), and 95 students (53 boys, 42 girls) without an illustration or a warning $(I-$ $W$ - condition).

\section{Material and Procedure}

The students received a paper-and-pencil test with the $10 P$-items and the 10 complementary $S$-items from the study of Verschaffel et al. (1994), which they had to solve individually ${ }^{2}$. As in the original study, the word problems were presented so that the $S$-items and $P$-items were mixed and that the $S$-item and the $P$-item from a given item pair were not presented immediately after each

\footnotetext{
${ }^{2}$ In the original study of Verschaffel et al. (1994), the items $S 10$ and $P 10$ were accompanied with a drawing of, respectively, a cylindrical and a cone-shaped flask. Since the problem text did not say anything about the shape of the flask, these pictures were-in terms of Elia and Philippou's (2004) classification-informational. With a view to stick to the design of Verschaffel et al.'s (1994) original study, in the present studies we removed these informational pictures and rephrased the original text slightly so that it contained the essential information about the shape of the flask.
} 
other. There were two test versions with a different (fixed) order of the problems to exclude order effects. The test was split into two sets of $10 S$-items and $P$-items presented at the beginning and at the end of a single lesson, with a break in between, in which a different assignment was given.

The paper-and-pencil test was administered by the class teacher on an ordinary school day during an ordinary mathematics class, with a view to embed the test within the normal culture of the mathematics class. Each $P$-item or $S$-item was followed by an answer area and a comments area. Students were instructed to write, for each item, their answer in the answer area and their calculations and/or possible other comments in the comments area. The students were not allowed to use a calculator, or to ask questions. However, if the teacher could not prevent a student from raising a question before or during the test, they were asked to answer it individually rather than for the whole class and as neutrally as possible. These instructions were the same for all four conditions.

As already mentioned, there were two factors that were manipulated in this study: the presence or absence of an illustration and of a warning. The illustrations that we presented next to the $S$ items and $P$-items were representational illustrations as in the categorization of Elia and Philippou (2004). The illustrations for the $P$-items were drawn so that they evoked the overall real-world scene to which they referred. They were printed in color and were positioned besides the problem statements. See Table 1 for some examples of $P$-items accompanied with an illustration.

The warning alerted students about the fact that the test may also involve some difficult and tricky problems that are not as simple and straightforward as they may first seem. Students were

TABLE 1

Examples of $P$-items With Illustration

\begin{tabular}{|c|c|}
\hline Problematic items (P-items) & Illustration \\
\hline$P 2$ & $\begin{array}{l}\text { Steve has bought } 4 \text { planks that are } 2.5 \mathrm{~m} \text { each. } \\
\text { How many planks of } 1 \mathrm{~m} \text { can he get out of these } \\
\text { planks? }\end{array}$ \\
\hline$P 6$ & $\begin{array}{l}\text { Bruce and Alice go to the same school. Bruce lives } \\
\text { at a distance of } 17 \mathrm{~km} \text { from the school and } \\
\text { Alice at } 8 \mathrm{~km} \text {. How far do Bruce and Alice live } \\
\text { from each other? }\end{array}$ \\
\hline$P 9$ & $\begin{array}{l}\text { A man wants to have a rope long enough to stretch } \\
\text { between two poles } 12 \mathrm{~m} \text { apart, but he has only } \\
\text { pieces of rope } 1.5 \mathrm{~m} \text { long. How many of these } \\
\text { pieces would he need to tie together to stretch } \\
\text { between the poles? }\end{array}$ \\
\hline
\end{tabular}


stimulated to be attentive for those problems and were invited for each item, to write down not only their answers but also possible additional comments or queries. This warning was given orally by the class teacher before the start of the test and was also printed on the first page of the test booklet. Moreover, a short version of the warning was repeated in the header section of each subsequent page. The students in the conditions without a warning (the $I-W-$ condition and $I+W-$ condition) received only a short general oral and written instruction without any special warning.

\section{Analysis}

Given that the research questions and hypotheses only address the reactions of the students on the P-items, the analysis was restricted to the responses for those items. Students' reactions to the P-items were coded in exactly the same way as in the study of Verschaffel et al. (1994).

First, the answers on the $P$-items were divided into the following categories: expected answer (EA), technical error (TE), realistic answer (RA), no answer (NA), and other answer (OA). An answer was coded as EA if there was a straightforward application of the arithmetic operation(s) elicited by the word problem leading to a nonrealistic response. When students chose the solution path that led to an EA but made a computational mistake, their answer was coded as TE. Answers were considered as RA when they involved the use of real-world knowledge and realistic considerations concerning the problem situation, which led students to another answer than the expected one. Realistic answers involving a computational error were also coded as RA. An answer was coded as NA when a student did not write down any answer. Answers that could not be classified into one of the aforementioned categories were coded as OA. See Verschaffel et al. (1994) for a detailed overview of the scoring rules for all $P$-items.

After coding students' answers on the $P$-items into these different categories, we also looked in the comments area for possible additional traces of awareness of the realistic modeling difficulty involved in the $P$-item. When such a trace of a realistic consideration was found, even when it was minimal and/or not totally correct from a realistic point of view, a "+" was added to the student's response code for that item; when no trace was found, a "-" was added.

On the basis of the categorization of the students' notations in the answer area and in the comments area, the code RR (for realistic reactions) or NR (for nonrealistic reactions) was given. Realistic answers (RA+ and RA-) and those accompanied by real-world comments (EA+, TE+, $\mathrm{NA}+$, and $\mathrm{OA}+$ ) were coded as realistic reactions. The other answers (EA-, TE-, NA-, and $\mathrm{OA}-$ ) were considered as nonrealistic reactions.

The following example clarifies the coding of the students' answers. For the $P$-item "Steve has bought 4 planks of $2.5 \mathrm{~m}$ each. How many planks of $1 \mathrm{~m}$ can he saw out of these planks?" the answer " $4 \times 2.5 \mathrm{~m}=10$," without any further comment, was coded "EA-" because it is based on the expected straightforward application of the arithmetic operation that is hidden in the problem, without any further qualifying comment. When a student answered " 10 planks" but added the comment that "this would require that the 4 remaining pieces of $0.5 \mathrm{~m}$ were somehow put together," the answer was coded as "EA+" because the student showed awareness of the realistic modeling difficulty in his or her additional comments. The answer " $4 \times 2=8$ planks," without any further comment, was coded as "RA-," whereas the same answer complemented with the comment " 4 unusable pieces of $0.5 \mathrm{~m}$ are left" was coded "RA+." The first of these four 
illustrative reactions was ultimately coded as a nonrealistic reaction, whereas the latter three were coded as realistic reactions.

After coding students' responses on the $P$-items, the interrater reliability score was computed for $10.0 \%$ of the data. The codes of two researchers for $P$-items as realistic response or nonrealistic response were compared. A nearly perfect agreement was found $(K=.974)$.

To test for significant differences between the conditions, the coded responses (realistic response $=1$ or nonrealistic response $=0$ ) were analyzed with a logistic regression using the generalized linear mixed models approach in SAS. The generalized linear mixed models procedure allows nonnormal data (in our case binominal data) and correlations among responses (SAS Institute Inc., 2008). This approach takes into account the fact that test items are nested within students who in their turn are nested within classes (de Leeuw \& Meijer, 2008; SAS Institute Inc., 2008; Snijders \& Bosker, 1999).

\section{Results}

Taken together, the percentage of realistic responses over all conditions was $12.6 \%$. This percentage is slightly smaller than, in the study of Verschaffel et al. (1994), where 17.0\% realistic responses were observed. Despite this small difference, this overall result largely replicates previous findings and shows that Turkish students also respond very unrealistically to word problems in which they have to consider the realities of the context in order to arrive at a situationally meaningful answer.

The analysis of the percentages of realistic responses in the conditions revealed that this percentage was low in all four conditions: $9.7 \%$ in the $I-W-$ condition, $13.5 \%$ in the $I-$ $W+$ condition, $13.8 \%$ in the $I+W-$ condition and $13.1 \%$ in the $I+W+$ condition. To see if these small differences between the conditions were statistically significant, the responses were analyzed with a logistic regression. In this analysis, reaction (realistic or nonrealistic) was the

TABLE 2

Percentage of Realistic Responses Per Item Over All Conditions and the Total Number of Realistic Responses for Study 1

\begin{tabular}{|c|c|c|c|c|c|c|}
\hline & & \multicolumn{4}{|c|}{ Condition } & \multirow[b]{2}{*}{ Tota } \\
\hline & & $\begin{array}{c}\text { Illustration (+) } \\
\text { Warning (+) }\end{array}$ & $\begin{array}{c}\text { Illustration (+) } \\
\text { Warning (-) }\end{array}$ & $\begin{array}{c}\text { Illustration (-) } \\
\text { Warning (+) }\end{array}$ & $\begin{array}{c}\text { Illustration (-) } \\
\text { Warning (-) }\end{array}$ & \\
\hline$P 1$ & Friends & 2.0 & 9.3 & 5.6 & 5.3 & 5.5 \\
\hline$P 2$ & Plank & 10.8 & 6.2 & 1.9 & 1.1 & 5.0 \\
\hline$P 3$ & Water & 18.6 & 23.7 & 38.0 & 25.3 & 26.6 \\
\hline$P 4$ & Buses & 32.4 & 25.8 & 20.4 & 18.9 & 24.4 \\
\hline$P 5$ & Runner & 1.0 & 0.0 & 0.0 & 0.0 & 0.2 \\
\hline$P 6$ & School & 2.9 & 1.0 & 3.7 & 0.0 & 2.0 \\
\hline$P 7$ & Balloon & 58.8 & 69.1 & 63.0 & 46.3 & 59.5 \\
\hline$P 8$ & Age & 2.0 & 3.1 & 0.9 & 0.0 & 1.5 \\
\hline$P 9$ & Rope & 1.0 & 0.0 & 0.9 & 0.0 & 0.5 \\
\hline \multirow[t]{2}{*}{$P 10$} & Flask & 2.0 & 0.0 & 0.9 & 0.0 & 0.7 \\
\hline & Total & 13.1 & 13.8 & 13.5 & 9.7 & 12.6 \\
\hline
\end{tabular}


dependent variable and illustration, alert and gender were the independent variables. The analysis revealed that there was no main effect of illustration, $F(1,3618)=0.80, p=.370$, or warning, $F(1,3618)=0.02, p=.877$, and no statistically significant interaction between the two, $F(1$, $3618)=0.16, p=.692$. So there were no effects of both manipulations, not even when presented together. For an overview of the percentages of realistic responses per condition and per item, see Table 2.

We also looked for differences in the responses of boys and girls, but no statistically significant effect of gender was found, $F(1,3618)=0.98, p=.321$. There was also no interaction between gender and illustration, $F(1,3618)=2.23, p=.135$, or gender and warning, $F(1,3618)=0.13$, $p=.722$.

\section{Conclusion}

This study shows, first, that the strong tendency to exclude realistic considerations when solving school word problems is also present in Turkish upper elementary school children. However, the major goal of the study was to see if the presence of an illustration and/or warning would increase the number of realistic reactions on $P$-items. No main effect of illustration or warning was found, so Hypotheses 1 and 2 were rejected. There was also no interaction between illustration and warning, so Hypothesis 3 was also rejected, as were Hypotheses 4 and 5, both dealing with the impact of gender.

\section{STUDY 2: A STUDY WITH BELGIAN STUDENTS}

For this study, we held the same hypotheses and expectations as in Study 1.

\section{Method}

The method was essentially the same as in Study 1. Hereafter, we list only the few points of difference with the first study.

\section{Participants}

The participants were 233 upper elementary school children (92 boys, 104 girls) from 12 classes from five schools in the Flemish-speaking part of Belgium. All students were in the fifth grade $(10-11$ years old). The participating classes were assigned to the four conditions on the basis of the mean percentile scores on a frequently-used general mathematics achievement test in Flanders (Dudal \& Deloof, 2004). In doing so, we could equalize the mean mathematics achievement levels in the four conditions. As a result, 55 students ( 21 boys, 34 girls) received the problems accompanied with an illustration $(I+W-$ condition), 60 students (22 boys, 38 girls) with a warning ( $I-W+$ condition), 56 students (22 boys, 34 girls) with an illustration and a warning $(I+W+$ condition), and 62 students ( 27 boys, 35 girls) without an illustration or warning $(I-W-$ condition$)$. 


\section{Material and Procedure}

The paper-and-pencil test that students received in this study consisted of 16 word problems from Verschaffel et al.'s (1994) study. Because the available time for the test administration was somewhat smaller than in the first study, we dropped two item pairs. We decided to remove the balloons item and the age item, and their corresponding $S$-items. As in Study 1, the regular class teacher presented all 16 items in a mixed order. Two test versions with a different order of the $S$-items and $P$-items were applied. The instructions were the same as in Study 1, except that students had only $50 \mathrm{~min}$ to complete the test.

\section{Analysis}

The coding of students' answers was exactly the same as in Study 1 . The interrater reliability score was computed for $12.0 \%$ of the data. As in Study 1, a nearly perfect agreement was found between two researchers $(K=.969)$.

Again, as in Study 1, the responses were analysed with a logistic regression using a generalize linear mixed models approach in SAS.

\section{Results}

First, only $11.9 \%$ of the reactions were coded as realistic. This percentage is slightly lower than in Study 1 (12.6\%). This may be caused by the fact that the balloons item was removed from the test. The balloons item is typically one of the few items that elicit rather high percentages of realistic reactions (Verschaffel et al., 2000). Thus, these results again showed that students have a strong tendency to exclude their knowledge of everyday life when solving word problems.

Second, as in Study 1, we found only small differences in the percentages of realistic reactions for the distinct conditions. The $I+W+$ condition was the condition with the most realistic reactions $(13.6 \%)$, followed by the $I-W-$ condition (12.3\%), the $I-W+$ condition $(11.3 \%)$ and the

TABLE 3

Percentage of Realistic Responses Per Item Over All Conditions and the Total Number of Realistic Responses for Study 2

\begin{tabular}{|c|c|c|c|c|c|c|}
\hline & & \multicolumn{4}{|c|}{ Condition } & \multirow[b]{2}{*}{ Tota } \\
\hline & & $\begin{array}{c}\text { Illustration (+) } \\
\text { Warning (+) }\end{array}$ & $\begin{array}{c}\text { Illustration (+) } \\
\text { Warning (-) }\end{array}$ & $\begin{array}{c}\text { Illustration (-) } \\
\text { Warning (+) }\end{array}$ & $\begin{array}{c}\text { Illustration (-) } \\
\text { Warning (-) }\end{array}$ & \\
\hline$P 1$ & Friends & 16.1 & 7.3 & 18.3 & 9.7 & 12.9 \\
\hline$P 2$ & Plank & 16.1 & 14.5 & 16.7 & 19.4 & 16.7 \\
\hline$P 3$ & Water & 12.5 & 16.4 & 10.0 & 12.9 & 12.9 \\
\hline$P 4$ & Buses & 48.2 & 40.0 & 35.0 & 40.3 & 40.8 \\
\hline$P 5$ & Runner & 1.8 & 0.0 & 1.7 & 3.2 & 1.7 \\
\hline$P 6$ & School & 8.9 & 3.6 & 5.0 & 9.7 & 6.9 \\
\hline$P 9$ & Rope & 5.4 & 1.8 & 1.7 & 0.0 & 2.1 \\
\hline \multirow[t]{2}{*}{$P 10$} & Flask & 0.0 & 0.0 & 1.7 & 3.2 & 1.3 \\
\hline & Total & 13.6 & 10.5 & 11.3 & 12.3 & 11.9 \\
\hline
\end{tabular}


$I+W-$ condition $(10.5 \%)$. As in Study 1 , the coded answers were analyzed with a generalize linear mixed models procedure with illustration, warning and gender as independent variables. A comparison between the four conditions showed, as in Study 1, that there was no main effects of illustration, $F(1,1631)=0.04, p=.847$, or warning, $F(1,1631)=0.00, p=.987$. As in Study 1 , there was also no statistically significant interaction effect between these two independent variables, $F(1,1631)=1.16, p=.282$. For an overview of the percentages of realistic reactions per condition and per item, see Table 3.

Furthermore, there was no main effect of gender, $F(1,1631)=1.67, p=.197$; or an interaction between gender and illustration, $F(1,1631)=0.19, p=.664$; and gender and warning, $F(1$, $1631)=0.87, p=.352$.

\section{Conclusion}

As Study 1, this study replicated previous findings about the unrealistic nature of students' solutions of word problems (as reviewed in Verschaffel et al., 2000, 2009). Moreover, also as in Study 1, presenting an illustration or a warning had no effect, so Hypotheses 1 and 2 were again rejected. Even the combination of an illustration and a warning did not lead to a statistically significant increase of realistic reactions, meaning that Hypothesis 3 also had to be rejected. The same was the case for Hypothesis 4 and 5 about gender differences.

\section{GENERAL CONCLUSION AND DISCUSSION}

We carried out two kinds of manipulations to enhance students' tendency to model and solve word problems with a realistic modeling complexity $(P$-items) in an appropriate way. The first was the presence of a representational illustration, which was supposed to help students both cognitively and motivationally with the construction of a rich and realistic situational model of the problem. The second manipulation was the presence of a warning, aiming at making students alert of the nontrivial nature of the test and putting them in a setting that allowed them to give situationally appropriate reactions. We were particularly interested in the combined effect of these two manipulations. Thereby, the expected positive impact of the illustration would be facilitated by a warning. In addition, we examined the subject characteristic gender.

In general, the results were consistent and disappointing in the sense that in both studies neither the presence of the illustrations, nor the presence of a warning nor even the combination of the two manipulations resulted in an increase in the number of realistic reactions. There were also no effects of gender. Very similar results were obtained with two large and socioculturally different groups of students (402 Turkish and 233 Flemish fifth-grade students from various schools). This strengthens the validity and generalizability of our findings, and provides thus further strong empirical evidence for the very strong and persistent nature of traditionally schooled students' tendency to approach and handle school word problems in a nonrealistic way.

To explain the absence of a positive effect of the illustrations, we first may rely on cognitive theories such as Sweller's (2005) cognitive load theory or Schnotz and Bannert's (2003; see also Schnotz, 2005) integrated model of text and picture comprehension. According to cognitive load theory, the positive impact of the illustrations may have been attenuated by the negative impact of the extra cognitive load they put on the working memory. Sweller (2005) discussed three categories 
of cognitive load: (a) extraneous cognitive load (caused by an inappropriate instructional design); (b) intrinsic cognitive load (caused by the natural complexity of the information); and (c) germane cognitive load (effective cognitive load). Cognitive load theory predicts an increase of extraneous cognitive load when attention must be divided between different sources of visual information that are essential for understanding (equivalent to the split-attention effect). This may result in a decrease in performance ${ }^{3}$. The fact that information coming from two different sources must be mentally integrated is assumed to impose extra load on the working memory. This is exactly why, according to Schnotz's (2005) integrated model of text and picture comprehension, written text and pictures that both enter the visual channel, need to be presented as closely as possible to each other. Accordingly, the illustrations may not have led to a positive effect in our studies, because students had to divide their scarce attentional resources between the text and the illustration, causing a problematic heavy load on the working memory. Sweller (2005) argued that the split attention effect is only applicable when both sources are essential for understanding. Although, according to our definition, the representational illustrations that were used in the present study did not contain essential information, it could be argued that some students may have approached them as containing essential information. So, the split-attention effect still may have occurred.

In the case of nonessential information, cognitive load theory involves another mechanism that may explain why the provision of an extra picture may not be helpful, namely the redundancy effect. This effect is assumed to occur when there are two sources of information with essentially the same content, making the second information source redundant. In those cases, the information coming from the second source puts also unnecessary extra load on working memory, which can result in lower performance. That is why Schnotz (2005) argued that learners with sufficiently high prior knowledge about the content perform better with only one information source (text or illustration). It could be argued that the content of the representational illustrations in our studies was redundant, and therefore may have hindered the students-who typically had enough prior knowledge to understand the content of the word problems and build a mental model of them-instead of helping them. Sweller argues that cognitive load can be reduced by physically integrating the multiple sources of information, and by eliminating redundant information. Taking into account the two aforementioned insights from cognitive load theory, it would be interesting to replicate our studies with various kinds of illustrations (e.g., also illustrations containing essential information) and/or with alternative combinations of text and pictures such as comic strips where text and pictures are integrated.

However, it is our conviction that the absence of a positive effect of pictures in the present study cannot be explained in purely cognitive terms alone, as was done in the two aforementioned theoretical accounts. We think that it also requires an explanation that focuses on the sociocultural or mathematics educational context wherein the students have learnt to solve word problems.

In this respect, we are inclined to conclude that the pictures did not work because their impact was still not a strong enough antidote against the pressure from the mathematics classroom practice and culture in which these students had, for many years, solved hundreds of word problems (Gravemeijer, 1997; Greer, 1997; Reusser \& Stebler; 1997a; Verschaffel et al., 2000; Wyndhamn \& Säljö, 1997). Students have had a long-lasting participative involvement in a specific culture of practice (Lave, 1992), characterized by implicitly and gradually acquired values and

\footnotetext{
${ }^{3}$ Whether the increase in extraneous cognitive load will actually lead to a decrease in performance will depend on the total load (the sum of extraneous, intrinsic, and germane load) on working memory (Sweller, 2005).
} 
norms about how word problems should be approached, modeled and solved. The impact of this involvement may have been so overwhelming that the addition of a clarifying illustration was not powerful enough to seriously counter the (negative) influence of this practice and culture.

Combining elements from the aforementioned cognitive and sociocultural perspectives, we believe that, at a more specific process level, the pictures were ineffective for three reasons. First, because the students simply did not look at them (influenced by their previous experiences with pictures in the mathematics textbooks, from which they may have concluded that they are typically not helpful). Second, because they did look at the illustrations but did not activate the associated real-world knowledge as part of their mental model of the problem situation (because they have learnt to represent and solve word problems in a restricted way focusing on the paradigmatic mathematical structure underlying the problem rather than on the particularities of its narrative structure, see Chapman, 2006, and Depaepe, De Corte, \& Verschaffel, 2010). Or third, because they did look at the illustrations and did activate the relevant real-world knowledge but finally did not generate a realistic reaction because of a more or less deliberate decision not to violate implicit norms about solving word problems in the mathematics class. Examples of such norms are that all problems are solvable, that every number in the problem is relevant and that all necessary information is explicitly given in the problem statement (see Caldwell, 1995; Reusser \& Stebler, 1997a; Schoenfeld, 1991, Verschaffel et al., 2000). More research is needed to unravel the importance of these three possible (complementary) explanatory factors.

As far as the absence of a positive effect of the warning is concerned, one could ask whether the same effect would have been found if we would have worked with another operationalization. This could be a more subject specific and/or problem specific form of warning, as used in other studies of Reusser and Stebler (1997a) or Verschaffel et al. (1999). In this respect, it may also be interesting to explore the impact of warnings that explicitly invite the students to pay attention to the illustrations and/or to try to visualize the problem situation with help of these illustrations.

Last, from a practical perspective, little can be concluded from both studies, except that textbook writers and teachers who want to increase students' tendency to interpret, model and solve word problems in a realistic way, should not expect too much from representational illustrations and/or simple warnings, as long as students are presented with these problems in the context of a traditional word problem solving lesson or test.

\section{AUTHOR NOTES}

Tinne Dewolf is a Ph.D student at the Centre for Instructional Science and Technology (CIP\&T) at the KU Leuven. Her research interests lie in the way elementary school children solve mathematical word problems in the mathematics class, more specifically their tendency to exclude realistic considerations when solving mathematical word problems. Wim Van Dooren, Ph.D, is an assistant professor in educational psychology at the CIP\&T at the KU Leuven. His research interests lie in mathematical problem solving, the role of heuristics and intuitions in problem solving, number sense, misconceptions in science and mathematics, conceptual change, and statistics education. Emre Ev Cimen, Ph.D, is a lecturer in mathematics education at Eskişehir Osmangazi University. Her research interests lie in the topics of mathematical power, conceptual understanding and procedural knowledge, and misbeliefs about problem solving. Lieven Verschaffel, Ph.D, is a full professor in educational psychology at the CIP\&T at the KU Leuven. His major research 
interests are in mathematical problem solving, number sense and estimation, mental and written computation, misconceptions in mathematics, and affective aspects of mathematics teaching and learning.

\section{REFERENCES}

Agathangelou, S., Gagatsis, A., \& Papakosta, V. (2008, September). The role of verbal description, representational and decorative picture in mathematical problem solving. Paper presented at the Conference of Five Cities, Nicosia, Cyprus. Retrieved from http://www.pre.aegean.gr/labs/mathlab/conference2011/icon/First\%20Conference\%20of\%205cities. pdf

Blum, W., \& Niss, M. (1991). Applied mathematical problem solving, modelling, applications, and links to other subjects-State, trends, and issues in mathematics education. Educational Studies in Mathematics, 22, 37-68. doi: 10.1007/BF00302716

Boaler, J. (1994). When do girls prefer football to fashion? An analysis of female underachievement in relation to 'realistic' mathematic contexts. British Educational Research Journal, 20, 551-564. doi: 10.1080/0141192940200504

Burkhardt, H. (1994). Mathematical applications in school curriculum. In T. Husén \& T. N. Postlethwaite (Eds.), The international encyclopedia of education (2nd ed., pp. 3621-3624). Oxford, UK: Pergamon Press.

Caldwell, L. (1995). Contextual considerations in the solution of children's multiplication and division word problems (Master's thesis). Queen's University, Belfast, UK.

Carney, R. N., \& Levin, J. R. (2002). Pictorial illustrations still improve students' learning from text. Educational Psychology Review, 14, 5-26. doi: 10.1023/A:1013176309260

Chapman, O. (2006). Classroom practices for context of mathematics word problems. Educational Studies in Mathematics, 62, 211-230. doi: 10.1007/s10649-006-7834-1

DeFranco, T. C., \& Curcio, F. R. (1997). A division problem with a remainder embedded across two contexts: Children's solutions in restrictive versus real-world settings. Focus on Learning Problems in Mathematics, 19, 58-72.

de Leeuw, J., \& Meijer E., (2008). Handbook of multilevel analysis. New York, NY: Springer.

Depaepe, F., De Corte, E., \& Verschaffel, L. (2010). Teachers' approaches towards word problem solving: Elaborating or restricting the problem context. Teaching and Teacher Education, 26, 152-160. doi: 10.1016/j.tate.2009.03. 016

Dudal, P., \& Deloof, G. (2004). LVS-VCLB/Leerlingvolgsysteem. Wiskunde: Toetsen 5-Basisboek [Student tracking system: Mathematics: Tests 5-Basic book]. Antwerpen, Belgium: Garant.

Elia, I., Gagatsis, A., \& Demetriou, A. (2007). The effects of different modes of representation on the solution of one-step additive problems. Learning and Instruction, 17, 658-672. doi: 10.1016/j.learninstruc.2007.09.011

Elia, I., \& Philippou, G. (2004). The functions of pictures in problem solving. In M. J. Hoines \& A. B. Fuglestad (Eds.), Proceedings of the 28th Conference of the International Group for the Psychology of Mathematics Education (Vol. 2., pp. 327-334). Bergen, Norway: University College.

Gravemeijer, K. (1997). Solving word problems: A case of modelling? Commentary. Learning and Instruction, 7 , 389-397. doi: 10.1016/S0959-4752(97)00011-X

Greer, B. (1993). The mathematical modeling perspective on wor(l)d problems. Journal of Mathematical Behavior, 12, 239-250.

Greer, B. (1997). Modelling reality in mathematics classrooms: The case of word problems. Learning and Instruction, 7 , 293-307. doi: 10.1016/S0959-4752(97)00006-6

Hidalgo, M. C. (1997). L'activation des connaissances à propos du monde réel dans la résolution de problèmes verbaux en arithmétique [The activation of real-world knowledge in solving arithmetic word problems] (Unpublished doctoral dissertation).Quebec City, Quebec, Canada Université Laval.

Inoue, N. (2001). The role of personal interpretation in mathematical problem solving: Enhancing the relevance of mathematical learning to everyday experience. Internal report, Teachers College, Columbia University, New York, NY.

Lave, J. (1992). Word problems: A microcosm of theories of learning. In P. Light \& G. Butterworth (Eds.), Context and cognition: Ways of learning and knowing (pp. 74-92). New York, NY: Harvester Wheatsheaf.

Mayer, R. E. (1997). Multimedia learning: Are we asking the right questions? Educational Psychologist, 32, 1-19. doi: 10.1207/s15326985ep3201_1 
Mayer, R. E. (2005). Cognitive theory of multimedia learning. In R. E. Mayer (Ed.), The Cambridge handbook of multimedia learning (pp. 31-48). New York, NY: Cambridge University Press.

Nesher, P. (1980). The stereotyped nature of school word problems. For the Learning of Mathematics, 1, 41-48.

Paivio, A. (1986). Mental representations. A dual coding approach. New York, NY: Oxford University Press.

Reusser, K., \& Stebler, R. (1997a). Every word problem has a solution-The social rationality of mathematical modeling in schools. Learning and Instruction, 7, 309-327. doi: 10.1016/S0959-4752(97)00014-5

Reusser, K., \& Stebler, R. (1997b, August). Realistic mathematical modelling through the solving of performance tasks. Paper presented at the 7th European Conference for Research on Learning and Instruction, Athens, Greece.

Säljö, R., \& Wyndhamn, J. (1993). Solving everyday problems in the formal setting: An empirical study of the school as context for thought. In S. Chaiklin \& J. Lave (Eds.), Understanding practice: Perspectives on activity and context (pp. 327-342). Cambridge, UK: Cambridge University Press.

SAS Institute Inc. (2008). SAS/STAT ${ }^{\circledR} 9.2$ user's guide. Cary, NC: Author.

Schnotz, W. (2005). An integrated model of text and picture comprehension. In R. E. Mayer (Ed.), The Cambridge handbook of multimedia learning (pp. 49-69). New York, NY: Cambridge University Press.

Schnotz, W., \& Bannert, M. (2003). Construction and interference in learning from multiple representation. Learning and Instruction, 13, 141-156. doi: 10.1016/S0959-4752(02)00017-8

Schoenfeld, A. H. (1991). On mathematics as sense-making: An informal attack on the unfortunate divorce of formal and informal mathematics. In J. F. Voss, D. N. Perkins, \& J. W. Segal (Eds.), Informal reasoning and education (pp. 311-343). Hillsdale, NJ: Erlbaum.

Snijders, T., \& Bosker, R. (1999). Multilevel analysis: An introduction to basic and applied multilevel analysis. London, UK: Sage.

Sweller, J. (2005). Implications of cognitive load theory for multimedia learning. In R. E. Mayer (Ed.), The Cambridge handbook of multimedia learning (pp. 19-30). New York, NY: Cambridge University Press.

Van Lieshout, E. C., Verdwaald, A., \& Van Herk, J. (1997, August). Suppression of real-world knowledge and demand characteristics in word problem solving. Paper presented at the 7th European Conference on Learning and Instruction, Athens, Greece.

Verschaffel, L. (2002). Taking the modeling perspective seriously at the elementary school level: promises and pitfalls (Plenary lecture). In A. Cockburn \& E. Nardi (Eds.), Proceedings of the 26th Annual Conference of the International Group for the Psychology of Mathematics Education (Vol. 1, pp. 64-82). Norwich, UK: University of East Anglia.

Verschaffel, L., De Corte, E., \& Lasure, S. (1994). Realistic considerations in mathematical modeling of school arithmetic word problems. Learning and Instruction, 4, 273-294. doi: 10.1016/0959-4752(94)90002-7

Verschaffel, L., De Corte, E., \& Lasure, S. (1999). Children's conceptions about the role of real-world knowledge in mathematical modelling: Analysis and improvement. In W. Schnotz, S. Vosniadou, \& M. Carretero (Eds.), New perspectives on conceptual change (pp. 175-189). Oxford, UK: Elsevier Science.

Verschaffel, L., Greer, B., \& De Corte, E. (2000). Making sense of word problems. Lisse, The Netherlands: Swets \& Zeitlinger.

Verschaffel, L., Greer, B., Van Dooren, W., \& Mukhopadhyay, S. (2009). Words and worlds: Modeling verbal descriptions of situations. Rotterdam, The Netherlands: Sense Publishers.

Wyndhamn, J., \& Säljö, R. (1997). Word problems and mathematical reasoning-A study of children's mastery of reference and meaning in textual realities. Learning and Instruction, 7, 361-382. doi: 10.1016/S0959-4752(97)000091

Yoshida, H., Verschaffel, L., \& De Corte, E. (1997). Realistic considerations in solving problematic word problems: Do Japanese and Belgian children have the same difficulties? Learning and Instruction, 7, 329-338. doi: 10.1016/S09594752(97)00007-8 